\title{
URINARY EXCRETION OF ACID MUCOPOLYSACCHARIDES BY PATIENTS WITH RHEUMATOID ARTHRITIS ${ }^{1}$
}

\author{
By NICOLA DI FERRANTE 2
}

(From the Medical Department, Brookhaven National Laboratory, Upton, N. Y.)

(Submitted for publication March 25, 1957; accepted June 13, 1957)

Several methods have been described for the determination of urinary acid mucopolysaccharides $(1-4)$. It has been found that in normal individuals the daily urinary excretion varies with age and sex $(4,5)$. A few attempts have been made to correlate urinary excretion of acid mucopolysaccharides with different disease states. Craddock and Kerby (6) have reported that patients with impairment of renal function have a urinary excretion of acid mucopolysaccharides lower than that of normal individuals. They also found no significant differences between normal individuals and diabetic patients without renal involvement. In patients with rheumatoid arthritis Badin, Schubert, and Vouras (7) have demonstrated a high plasma concentration of acid mucopolysaccharides, but there have hitherto been no data available concerning their urinary excretion.

This paper presents data on the urinary excretion of acid mucopolysaccharides by patients with rheumatoid arthritis and discusses the identity of the urinary acid mucopolysaccharides excreted in this disease.

\section{MATERIAL AND METHOD}

The study was performed on eight patients hospitalized for active rheumatoid arthritis. All of them showed a moderately elevated erythrocyte sedimentation rate, low-grade fever, involvement of several joints, and typical radiographic alterations. All patients were untreated when the urine collection was started. Two of them, however (M.G. and P.C.), discontinued treatment a few days before the urine collection was started. Urinary acid mucopolysaccharides were determined according to the method described by Di Ferrante and Rich (4), by which the urinary acid mucopolysaccharides are precipitated, from an aliquot of the 24-hour urine, with cetyl-trimethyl-ammonium bromide. After removal of the precipitant the glucuronic acid content of the precipitate is determined. The results in Table I and in Figure 1 are expressed as mg. of glucuronic acid per 24 hours.

\footnotetext{
1 This work was supported by the Atomic Energy Commission.

2 Present address: Department of Biochemistry, University of Rochester, Rochester, N. Y.
}

In five patients (P.C., B.E., E.E., W.J., and G.A.) the urinary excretion of acid mucopolysaccharides was measured both before and during periods of oral treatment with sodium salicylate.

In order to collect an amount of urinary acid mucopolysaccharides sufficient for purification and analysis, 20 liters of pooled urine from patients with rheumatoid arthritis were adjusted to $\mathrm{pH} 5$ with $2 \mathrm{~N} \mathrm{HCl}$, and $8 \mathrm{Gm}$. of cetyl-trimethyl-ammonium bromide were added. After 24 hours at $0^{\circ} \mathrm{C}$., the fine precipitate present was collected, by filtration under suction, on a thin layer of Hyflo super-cel. The cake of Hyflo super-cel was then washed in a $250-\mathrm{ml}$. centrifuge bottle with several $150-\mathrm{ml}$. aliquots of 95 per cent ethyl alcohol saturated in $\mathrm{NaCl}$, until the supernatant obtained after centrifugation was colorless. The sediment was dried in a desiccator, under vacuum and in presence of paraffin chips, and then extracted three times with $30 \mathrm{ml}$. of distilled water. The aqueous extract was reprecipitated with three volumes of 95 per cent ethyl alcohol saturated in $\mathrm{NaCl}$. After 24 hours at $0^{\circ} \mathrm{C}$., the precipitate was collected by centrifugation, dissolved in $100 \mathrm{ml}$. of water and cleared of insoluble material by further centrifugation at 13,000 $\mathrm{G}$ for 30 minutes. To the clear solution obtained, $\mathrm{NaCl}$ was added to $0.58 \mathrm{M}$ final concentration. This solution was left at $0^{\circ} \mathrm{C}$. overnight and then centrifuged in a Spinco analytical centrifuge at 56,100 r. p. m. for 4 hours and 24 minutes (rotor $\mathrm{J}$ ). The supernatant was electrodialyzed and brought to dryness. ${ }^{3}$ It was dissolved again in $10 \mathrm{ml}$. of glycine- $\mathrm{NaCl}-\mathrm{HCl}$ buffer $\mathrm{pH} 1.45$, to which $5 \mathrm{mg}$. of crystallin pepsin * were added. The solution was incubated at $37^{\circ} \mathrm{C}$. for 24 hours. At the end of this period, $15 \mathrm{ml}$. of phosphate buffer $\mathrm{M} / 15, \mathrm{pH} 7.5$ and 10 mg. of crystallin trypsin 4 were added to the solution and incubation was resumed for an additional 24 hours. At the end of the incubation period, the solution was electrodialyzed and then filtered through a thin layer of Hyflo super-cel, under aspiration. The clear filtrate was brought to $50-\mathrm{ml}$. volume and then extracted three times with $20 \mathrm{ml}$. of 88 per cent phenol in water. The aqueous layer was lyophilized and the residue was dissolved in $10 \mathrm{ml}$. of water. After electrodialysis, the final volume was brought to $25 \mathrm{ml}$.

On aliquots of this solution the following determinations were performed:

${ }^{3}$ As will be published elsewhere, the sediment thus obtained has been identified as the urinary mucoprotein reacting with various viruses, described by Tamm, Bugher, and Horsfall (8).

- Mann Research Laboratories, Inc., New York, N. Y. 
1) Glucuronic acid, on four aliquots $0.2 \mathrm{ml}$. each according to the method of Dische (9), using glucurone as standard;

2) Nitrogen, on four aliquots $1 \mathrm{ml}$. each, according to the method described by Hiller, Plazin and Van Slyke (10);

3) A 5-ml. aliquot was hydrolyzed with $4 \mathrm{~N} \mathrm{HCl}$, in a sealed tube at $100^{\circ}$ for six hours. After the acid was evaporated and the dry residue dissolved in a minimal amount of water, part of the hydrolysate was used for hexosamine determination, according to a modification of the Elson-Morgan method (11); part was used for the chromatographic differentiation between glucosamine and galactosamine, according to the technique described by Gardell (12), and part was used for paper chromatography according to Hausmann's technique (13) for the detection of amino acids. This chromatogram was dried at $100^{\circ}$ for 10 minutes, then sprayed with a solution of 0.1 per cent ninhydrin in butanol containing 5 per cent collidine;

4) A 5-ml. aliquot was oxidized with concentrated $\mathrm{HNO}_{3}$ in a sealed tube for eight hours at $180^{\circ}$. The acid was removed by evaporation in a desiccator over $\mathrm{CaCl}_{2}$ and $\mathrm{NaOH}$ and the residue dissolved in redistilled water. On duplicate aliquots of this hydrolysate the sulfur was determined, as

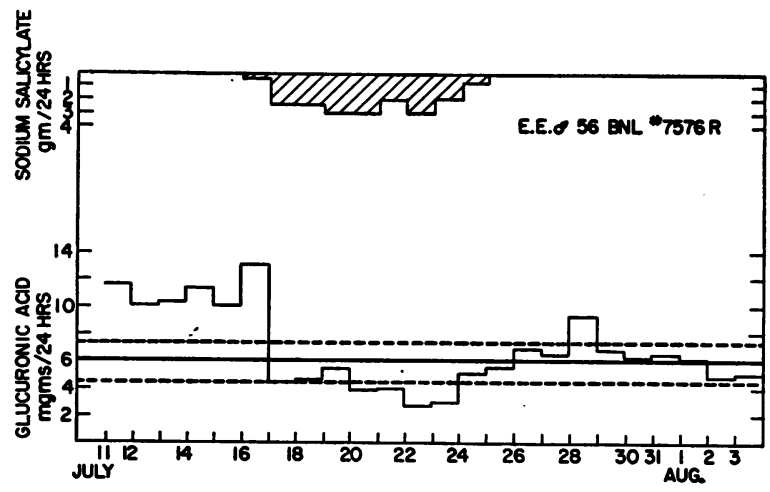

Fig. 1. Influence of Sodium Salicylate AdminisTRATION ON URINARY EXCRETION OF ACID MucopolysaCcharides in Patients with Rheumatoid Arthritis

Mean value for normal men (- $\longrightarrow$ ) and its range (- - - ) are also indicated.

sulfate, by conductometric titration with a standard solution of $\mathrm{BaCl}_{2}$, using a simple electric circuit, modified from that given by Shedlovsky (14);

5) Paper chromatography, according to the method of Kerby (15). The paper was stained with a solution of 0.1 per cent toluidine blue in 30 per cent ethyl alcohol and the excess of stain was removed

Table I

Urinary excretion of acid mucopolysaccharides by patients with rheumatoid arthritis, before and during treatment

\begin{tabular}{|c|c|c|c|}
\hline Patients & Treatment & $\begin{array}{l}\text { Range } \\
\mathrm{mg} / 24 \mathrm{hr} \text {. }\end{array}$ & $\begin{array}{l}\text { Average } \\
\text { stand. dev. } \\
\text { mg/24 hr. }\end{array}$ \\
\hline P.C. 749 & None (6 days) & $5.1-6.2$ & $5.8 \pm .3$ \\
\hline & $\begin{array}{l}\text { Na Salicylate } 4.5 \mathrm{gm} / \mathrm{day} \\
(22 \text { days })\end{array}$ & $2.5-6.6$ & $4.2 \pm .6$ \\
\hline B.E. $\uparrow 39$ & $\begin{array}{c}\text { None ( } 5 \text { days) } \\
\text { Na Salicylate } 4.5 \mathrm{gm} / \text { day (12 days) }\end{array}$ & $\begin{array}{l}7.0-7.8 \\
2.6-6.0\end{array}$ & $\begin{array}{l}7.4 \pm .3 \\
4.5 \pm .6\end{array}$ \\
\hline E.E. $\sigma^{6} 57$ & $\begin{array}{l}\text { None (4 days) } \\
\text { Na Salicylate } 2.4 \mathrm{gm} / \text { day (9 days) }\end{array}$ & $\begin{aligned} 10.0 & -13.0 \\
2.7 & -5.4\end{aligned}$ & $\begin{array}{r}11.0 \pm .7 \\
3.9 \pm .6\end{array}$ \\
\hline W.J. ơ 34 & $\begin{array}{c}\text { None (6 days) } \\
\text { Na Salicylate } 4.5 \mathrm{gm} / \text { day (9 days) }\end{array}$ & $\begin{array}{l}6.5-9.4 \\
3.3-5.6\end{array}$ & $\begin{array}{l}8.1 \pm .8 \\
4.1 \pm .4\end{array}$ \\
\hline G.A. $\sigma^{\top} 55$ & $\begin{array}{l}\text { None (11 days) } \\
\text { Na Salicylate } 6.3 \mathrm{gm} / \text { day (13 days) }\end{array}$ & $\begin{array}{l}9.4-14.6 \\
4.0-9.4\end{array}$ & $\begin{array}{r}11.2 \pm .9 \\
5.6 \pm .9\end{array}$ \\
\hline w.w. Ơ 72 & None (5 days) & $8.9-9.8$ & $9.3 \pm .3$ \\
\hline H.F. O'56 & None (5 days) & $10.6-12.8$ & $11.9 \pm .6$ \\
\hline M.G. $\sigma^{\top} 46$ & None (14 days) & $4.7-10.0$ & $6.6 \pm .9$ \\
\hline \multicolumn{4}{|c|}{ Normal Subjects } \\
\hline Women & & $2.7-5.4$ & $3.7 \pm .2$ \\
\hline Men & & $4.4-7.2$ & $6.0 \pm .3$ \\
\hline
\end{tabular}


by rinsing the paper several times in a solution of 30 per cent ethyl alcohol, containing 1 per cent acetic acid;

6) Paper electrophoresis, for six hours at $0^{\circ}$ and 200 volts, using Whatman No. 3 filter paper and acetate buffer $\mathrm{pH} 4.6,0.1 \mu$. The paper was stained in the same manner as in Procedure 5. In order to compare the chromatographic and electrophoretic behavior of the urinary mucopolysaccharides from patients with rheumatoid arthritis with that of the mucopolysaccharides from normal human urine (prepared as reported elsewhere (16)), in Procedures 5 and 6 roughly equal amounts of each were applied on the paper on separate spots. Skeletal chondroitinsulfate and hyaluronate from human umbilical cords $^{5}$ were also applied on the paper as reference standards;

7) Incubation with bacterial hyaluronidase. Two hundred micrograms of acid mucopolysaccharides from urine of patients with rheumatoid arthritis and 200 micrograms of acid mucopolysaccharides from normal human urine were incubated, in duplicate, with 100 turbidity reducing units of bacterial hyaluronidase. ${ }^{6}$ The extent of depolymerization of the two substrates after 30 minutes of incubation was measured using the turbidimetric method described by Di Ferrante (17).

\section{RESULTS}

Table I summarizes the values obtained in patients with rheumatoid arthritis, before and during treatment with sodium salicylate. The normal values for women and men, as determined with the same method (4), are also included. The differences between the values of untreated pa-

- Worthington Biochemical Sales Company, Freehold, New Jersey.

- Obtained through the kindness of Dr. K. W. Thompson, Organon Inc., Orange, New Jersey. tients with rheumatoid arthritis and the values of normal individuals are statistically significant ( $p<0.01$ ), except in patient M.G. In the five patients treated with salicylate, the fall in the mucopolysaccharides excretion during treatment is statistically significant ( $p$ of difference $<0.01$ ).

Figure 1 shows in detail the urinary excretion of acid mucopolysaccharides in patient E.E. before, during, and after sodium salicylate administration.

The possibility that some dialyzable material, containing glucuronic acid, could be partially responsible for the color obtained with the carbazole reagent and that the effect of salicylate could be due to changes in such component, was investigated. Extensive dialysis of solutions of the urinary material precipitated with cetyl-trimethylammonium bromide demonstrated the absence of dialyzable material able to develop color with the carbazole reagent, either before or during treatment with salicylate.

To investigate the possibility that products of excretion of sodium salicylate could interfere with the reaction between acid mucopolysaccharides and the precipitant, a recovery test was conducted, adding $1 \mathrm{mg}$. and $0.1 \mathrm{mg}$. of skeletal chondroitinsulfate to duplicate $30-\mathrm{ml}$. aliquots of urine obtained from patients under salicylate treatment. The recovery ranged between 94 and 104 per cent.

In Table II are presented the molar ratios of nitrogen, sulfur, glucuronic acid and glucosamine to galactosamine, for the mucopolysaccharides obtained from normal human urine and for those obtained from urine of patients with rheumatoid arthritis.

Table II

Molar ratios of some constituents of mucopolysaccharides from normal human urine and from urine of patients with rheumatoid arthritis

\begin{tabular}{lccccc}
\multicolumn{1}{c}{ Material } & Nitrogen & Sulfurł & $\begin{array}{c}\text { Glucuronic } \\
\text { acid }\end{array}$ & $\begin{array}{c}\text { Galacto- } \\
\text { samine(*) }\end{array}$ & $\begin{array}{c}\text { Glucosa- } \\
\text { mine }\end{array}$ \\
$\begin{array}{l}\text { Mucopolysaccharides } \\
\text { from normal human } \\
\text { urine }\end{array}$ & 1.75 & 1.10 & 1.27 & 1.00 & 0.10 \\
\hline $\begin{array}{l}\text { Mucopolysaccharides } \\
\text { from urine of patients } \\
\text { with rheumatoid arthritis }\end{array}$ & 3.57 & 1.19 & 1.83 & 1.00 & 0.53 \\
\hline
\end{tabular}

(*)Galactosamine is arbitrarily assigned a value of 1.00 .

¥ Nitrogen and sulfur figures are atoms $N$ and $S$ per molecule of galactosamine. 
The paper chromatogram of the hydrolyzed urinary mucopolysaccharides from patients with rheumatoid arthritis, developed according to Hausmann's technique and stained with ninhydrin, revealed, besides a major component having the same mobility as a standard of glucosamine and galactosamine hydrochloride, ${ }^{7}$ at least 10 additional components. On paper chromatography, according to Kerby (15), and on paper electrophoresis, the urinary mucopolysaccharides from normal individuals and from patients with rheumatoid arthritis presented a similar pattern, namely a fastmoving component having a mobility similar to that of a standard of skeletal chondroitin-sulfate, and another component, migrating at a rather slower rate, with a mobility similar to that of a standard of hyaluronate. Incubation for $30 \mathrm{~min}$ utes with 100 turbidity reducing units of bacterial hyaluronidase produced 30 per cent depolymerization of the preparation obtained from patients with rheumatoid arthritis and 15 per cent depolymerization of the preparation obtained from normal individuals. Incubation under the same conditions, for intervals of time shorter or longer than 30 minutes, demonstrated that the last interval allowed maximal depolymerization of the substrates.

\section{DISCUSSION}

The presence in normal human urine of an acid mucopolysaccharide similar to skeletal chondroitinsulfuric acid has been demonstrated (16). Both hyaluronic acid and chondroitinsulfuric acid have been found in normal human plasma (18). Recently, hyaluronic acid has been isolated in a relatively large amount from the sera of two patients with reticulum cell sarcoma and neuroblastoma (19). Considering that urinary acid mucopolysaccharides are present in urine obtained from the renal pelvis (5) and that their average molecular weight is approximately $10,000^{8}(16)$, it appears correct to assume that the urinary material derives from the similar one present in plasma.

The analytical data of Table II suggest the pos-

7 With the solvent systems used, glucosamine and galactosamine are not distinguished.

8 The average molecular weight of 10,000 was obtained for a preparation of urinary acid mucopolysaccharides previously incubated with trypsin and papain. An average value of 17,000 was obtained for a similar preparation not treated with proteolytic enzymes. sibility that the urinary mucopolysaccharides from normal individuals and from patients with rheumatoid arthritis are a mixture of chondroitinsulfate and hyaluronate. This possibility is supported by the following considerations: 1) 10 per cent and 35 per cent of the total hexosamine present in the preparations of urinary mucopolysaccharides from normal individuals and from patients with rheumatoid arthritis appear to be glucosamine. 2) The results of the enzymatic experiments are in good agreement with these values. In fact, incubation of aliquots of the two preparations with bacterial hyaluronidase produced respectively 15 per cent and 30 per cent depolymerization of the substrates. 3) The sulfur and the galactosamine of the two preparations are approximately in equimolar ratio. The excess of sulfur may be due to sulfur-containing amino acids from protein contaminants.

Is the different ratio chondroitinsulfate/hyaluronate in the two groups of individuals merely a consequence of the different techniques used for the purification of the urinary materials, or is it a reflection of some difference in the metabolism and/or excretion of acid mucopolysaccharides in the two groups? Analysis of several preparations of acid mucopolysaccharides obtained from normal human urine using the technique described here has demonstrated that approximately 30 per cent of the hexosamine present in them is glucosamine. Therefore, it seems correct to assume that the difference in hyaluronate content of the two preparations presented in Table II is due to the different techniques used for their purification.

The administration of sodium salicylate to patients with rheumatoid arthritis appears to reduce the previously elevated urinary excretion of acid mucopolysaccharides. No data are available on the effect of this drug on the plasma level of acid mucopolysaccharides in similar conditions. It has been reported, however, that the administration of cortisone, ${ }^{9}$ aspirin and gold, either together or separately, to patients with rheumatoid arthritis, reduces the elevated serum level of glycoproteins (20).

Several observations seem to prove that sodium salicylate decreases the uptake of sulfate- $S^{35}$ by slices of cartilage in vitro (21) and the hexosamine content of the skin in vivo (22), effects which have

${ }^{9}$ Brand name of 17-hydroxy-11-dehydrocorticosterone. 
been interpreted as indicative of inhibition in the synthesis of acid mucopolysaccharides produced by this drug. At present, however, it is not possible to state whether a decreased rate of synthesis is responsible for the diminution in the urinary excretion of acid mucopolysaccharides which follows the administration of salicylate to patients with rheumatoid arthritis.

\section{SUMMARY}

In patients with active, untreated rheumatoid arthritis the daily urinary excretion of acid mucopolysaccharides was higher than in normal individuals.

The administration of sodium salicylate to those patients decreased the urinary excretion of acid mucopolysaccharides.

Paper chromatography and paper electrophoresis, analytical and enzymatic data seem to indicate that the urinary acid mucopolysaccharides from normal individuals and those from patients with rheumatoid arthritis are a mixture of chondroitinsulfate and hyaluronate.

\section{ACKNOWLEDGMENT}

Sincere thanks are due to Dr. Donald D. Van Slyke for his continuous interest and helpful suggestions; also to Dr. Dominic D. Dziewiatkowski of the Rockefeller Institute for the use of the apparatus for sulfur determinations and for friendly criticism.

\section{REFERENCES}

1. Kobayasi, T., Biochemical studies on carbohydrates; polysaccharides from urine. J. Biochem., 1938, 28, 31.

2. Astrup, P., On the determination of heparin in blood plasma and urine. Acta pharmacol. et toxicol., $1947,3,165$.

3. Hamerman, D., Hatch, F. T., Reife, A., and Bartz, $\mathrm{K}$. W., Non-dialyzable material in normal human urine. J. Lab. \& Clin. Med., 1955, 46, 848.

4. Di Ferrante, N., and Rich, C., The determination of acid aminopolysaccharide in urine. J. Lab. \& Clin. Med., 1956, 48, 491.

5. Kerby, G. P., The excretion of glucuronic acid and of acid mucopolysaccharides in normal human urine. J. Clin. Invest., 1954, 33, 1168.
6. Craddock, J. G., Jr., and Kerby, G. P., Urinary excretion of acid mucopolysaccharides by diabetic patients. J. Lab. \& Clin. Med., 1955, 46, 193.

7. Badin, J., Schubert, M., and Vouras, M., Plasma polysaccharide fraction containing uronic acid, in normal subjects and in patients with rheumatoid arthritis. J. Clin. Invest., 1955, 34, 1317.

8. Tamm, I., Bugher, J. C., and Horsfall, F. L., Ultracentrifugation studies of a urinary mucoprotein which reacts with various viruses. J. Biol. Chem., 1955, 212, 125.

9. Dische, Z., A new specific color reaction of hexuronic acids. J. Biol. Chem., 1947, 167, 189.

10. Hiller, A., Plazin, J., and Van Slyke, D. D., A study of conditions for Kjeldahl determination of nitrogen in proteins. J. Biol. Chem., 1948, 176, 1401.

11. Sorensen, M., On the determination of glucosamine in proteins. Compt. rend. d. trav. du lab. Carlsberg., Série Chim., 1938, 22, 487.

12. Gardell, S., Separation on Dowex 50 ion exchange resin of glucosamine and galactosamine and their quantitative determination. Acta chem. Scandinav., 1953, 7, 207.

13. Hausmann, W., Amino acid composition of crystalline inorganic pyrophosphatase isolated from Bakers yeast. J. Am. Chem. Soc., 1952, 74, 3181.

14. Shedlovsky, T., in Technique of Organic Chemistry, Physical Methods of Organic Chemistry, 2nd ed., A. Weissberger, Ed. New York Interscience Publishing, Inc., 1949, Vol. I, Part II, p. 1676.

15. Kerby, G. P., Chromatographic separation of heparin and chondroitin sulfate. Proc. Soc. Exper. Biol. \& Med., 1953, 83, 263.

16. Di Ferrante, N., and Rich, C., The mucopolysaccharide of normal human urine. Clin. chem. acta, 1956, 1, 519.

17. Di Ferrante, N., Turbidimetric measurement of acid mucopolysaccharides and hyaluronidase activity. J. Biol. Chem., 1956, 220, 303.

18. Schiller, S., and Dewey, K. F., Isolation of chondroitinsulfuric acid from normal human plasma. Federation Proc., 1956, 15, 348.

19. Deutsch, H. F., Some properties of a human serum hyaluronic acid. J. Biol. Chem., 1957, 224, 767.

20. Kuhns, W. J., and Crittenden, J., Zone electrophoresis in studies of serum proteins, protein-bound polysaccharides and serum lipids in rheumatoid disease. J. Lab. \& Clin. Med., 1955, 46, 398.

21. Boström, H., and Mansson, B., The action of salicylates and related compounds on the sulphate exchange of chondroitin sulphuric acid. J. Pharm. \& Pharmacol., 1955, 7, 185.

22. Sobel, H., Zutrauen, H. A., and Marmorston, J., The collagen and hexosamine content of the skin of normal and experimentally treated rats. Arch. Biochem. \& Biophys., 1953, 46, 221. 